\title{
Detection of urinary survivin using a magnetic particles-based chemiluminescence immunoassay for the preliminary diagnosis of bladder cancer and renal cell carcinoma combined with LAPTM4B
}

\author{
YANG YANG, JIANJUN XU and QINGYUN ZHANG \\ Key Laboratory of Carcinogenesis and Translational Research (Ministry of Education), \\ Department of Clinical Laboratory, Peking University Cancer Hospital and Institute, Beijing 100142, P.R. China
}

Received November 24, 2017; Accepted March 16, 2018

DOI: $10.3892 / \mathrm{ol} .2018 .8317$

\begin{abstract}
The aim of the present study was to establish a simple step magnetic particles (MPs) based chemiluminescence enzyme immunoassay (CLEIA) for the detection of urinary survivin, and to investigate the diagnostic value of urinary survivin and lysosome-associated protein transmembrane- $4 \beta$ (LAPTM4B) in bladder cancer (BC) and renal cell carcinoma (RCC). The MPs-based CLEIA was developed on the basis of a double antibodies sandwich immunoreaction and luminol- $\mathrm{H}_{2} \mathrm{O}_{2}$ chemiluminescence system. The parameters of the method were optimized and evaluated. Urine samples were obtained from 200 BC patients, 81 RCC patients and 114 healthy individuals, and the MPs-based CLEIA method was employed to detect their urinary survivin. At the same time, the urinary LAPTM4B levels of the BC patients, RCC patients and the healthy controls were measured. The diagnostic efficiency of urinary survivin and LAPTM4B in BC and RCC was evaluated separately and jointly. A one-step MPs-based CLEIA for the detection of urinary survivin with good accuracy and precision was established. The signals were dependent on survivin concentrations in the range, 0 to $200 \mathrm{ng} / \mathrm{ml}$, and the detection limit was $0.949 \mathrm{ng} / \mathrm{ml}$. The areas under the receiver operating characteristic curves (AUC) were 0.771 in $\mathrm{BC}$ and 0.763 in RCC for urinary survivin. Urinary survivin was correlated with the tumor stage $(\mathrm{P}=0.002)$, lymph node metastasis $(\mathrm{P}=0.017)$, distant metastasis $(\mathrm{P}=0.005)$ and tumor size $(\mathrm{P}=0.02)$ of $\mathrm{BC}$; however, no association with the clinicopathological parameters in RCC was observed. The AUCs
\end{abstract}

Correspondence to: Dr Qingyun Zhang, Key Laboratory of Carcinogenesis and Translational Research (Ministry of Education), Department of Clinical Laboratory, Peking University Cancer Hospital and Institute, 52 Fucheng Road, Haidian, Beijing 100142, P.R. China

E-mail: zhqy_208@163.com

Key words: survivin, lysosome-associated protein transmembrane-4 $\beta$, chemiluminescence, bladder cancer, renal cell carcinoma for urinary LAPTM4B were 0.738 in BC and 0.704 in RCC, respectively. The AUCs for them combined were 0.842 in $\mathrm{BC}$ and 0.920 in RCC. The MPs-based CLEIA was performed well in the detection of urinary survivin. Urinary survivin and LAPTM4B could serve as potential biomarkers for the preliminary diagnosis of $\mathrm{BC}$ and $\mathrm{RCC}$, and in combination they a achieved a greater diagnostic performance.

\section{Introduction}

Bladder cancer (BC) and renal cell carcinoma (RCC) are two of the major tumors in urinary system. BC is the ninth most common cancer for both men and women (1) and kidney cancer is also among the ten most common malignant diseases in both sexes combined (2), of which the histological type is usually RCC. The urinary protein analysis could help discover non-invasive biomarkers for urinary system diseases $(3,4)$.

Urinary BTA and NMP22 are recognized as putative biomarkers for diagnosis of BC (5), but their applications are limited due to the relatively low sensitivity or specificity $(6,7)$. There is no definitively validated biomarker for diagnosis of RCC recommended in clinical practice so far (8).

Survivin is an important member of the Inhibitor of Apoptosis Protein family and the overexpression of survivin can be found in various tumors but barely in normal tissues (9). Urinary survivin has been proven to be a diagnostic marker in BC (10) but the diagnostic value of urinary survivin in RCC has not been fully elucidated. For now, the detection of survivin mainly employs quantitative sandwich enzyme immunoassay technique which requires multiple procedures and a relatively long period. Therefore, establishing a simple step method for the detection of urinary survivin is in urgent need.

Lysosome-associated protein transmembrane- $4 \beta$ (LAPTM4B) is a novel oncogene that was initially identified in hepatocellular carcinoma and LAPTM4B-35 protein was found to be overexpressed in various malignant tumors (11). But the expression of the protein in urine has not been studied yet.

In this study, we established a one-step magnetic particles (MPs)-based chemiluminescence enzyme immunoassay (CLEIA) for the detection of urinary survivin and applied 
it to the preliminary diagnosis of $\mathrm{BC}$ and $\mathrm{RCC}$. The urine LAPTM4B level was also measured in BC and RCC patients. We explored the combined diagnostic value of survivin and LAPTM4B for these two tumors in order to find a novel biological marker for the preliminary diagnosis of $\mathrm{BC}$ and RCC.

\section{Materials and methods}

Chemicals, reagents and apparatus. Incomplete freund's adjuvant (IFA), PEG, horseradish peroxidase (HRP; H1759), sodium borohydride (NaBH4; 10H3440), sodium m-periodate (NaIO4) (38F-0860) and (+)-biotin-N-hydroxysuccinimide (NHSB; HMBD0595 V) were from Sigma-Aldrich (Merck KGaA, Darmstadt, Germany). Hypoxanthine-aminopterin-thymidine and hypoxanthine-thymidine were from Corning Incorporated (Corning, NY, USA). MPs (Dynabeads M-280 Tosylactivated) with a average diameter of $2.8 \mu \mathrm{m}$ and the DynaMag-96 Side Skirted Magnet were purchased from Invitrogen Dynal AS (Oslo, Norway). Chemiluminescent substrates were purchased from Ke Yue Zhong Kai Co., Ltd. (Beijing, China). Protein-A/G sepharose (HiTrap Protein G HP) was from GE Healthcare Life Sciences (Buckinghamshire, UK). The human LAPTM4B enzyme-linked immunosorbent assay (ELISA) kit was purchased from Lifespan Biosciences (Seattle, WA, USA). BCA protein assay kit was obtained from Thermo Fisher Scientific, Inc. (Waltham, MA, USA). Phosphate-buffered saline (PBS) buffer and bovine serum albumin (BSA) were from ZSGB-Bio (Beijing, China). Tween-20, oxalic acid, glucose, vitamin $\mathrm{C}$, galactose, creatinine, urea, albumin were purchased from Solarbio (Beijing, China). Livin peptide was from Bioss (Beijing, China). The washing buffer was $0.01 \mathrm{M}$ PBS containing $0.05 \%$ (v/v) Tween-20 (PBST). The antibody diluent was $0.1 \mathrm{M}$ PBST with $1 \%$ BSA and 4\% PEG 6000, and it was used to dilute mAb-coated MPs and HRP-labeled mAb. SpectraMax L microplate reader from Molecular Devices, LLC (Sunnyvale, CA, USA) was employed to detect the chemiluminescence. The IKA ${ }^{\circledR}$ MS3 Digital (IKA, Staufen, Germany) was used for the shaking of the microplates. The white opaque 96-well flat-bottomed microplates were from Nunc (Roskilde, Denmark).

Experimental animals. Female Balb/c mice weighing 18-22 g were purchased from the Laboratory Animal Centre of Chinese Academy of Medical Sciences. The animal experiments were approved by the Animal Care Committee of Peking University (Beijing, China). The animal studies were performed in accordance with the Experimental Animal Management Ordinance approved by the Scientific and Technological Committee of China.

Preparation and purification of monoclonal antibody $(m A b)$ against survivin and preparation of standard series of survivin. The immunization and cell fusion procedure were carried out according to the methods described by Chang et al (12). Hybridoma cell lines (C6 and E6) were selected for ascites production in vitro and the details were carried out as described previously (12). Both the mAbs (C6 and E6) against survivin were first purified by the ammonium sulfate precipitation method to remove most of the hybrid protein and then purified by the protein $\mathrm{G}$ affinity chromatography columns. The purified mAbs were then subjected to sodium dodecyl sulfate-polyacrylamide gel electrophoresis (SDS-PAGE) analysis and commassie blue staining. Human recombinant sequence survivin protein $\mathrm{MS}_{2}$-survivin was produced by our laboratory (13). The standard series of survivin were prepared by diluting $\mathrm{MS}_{2}$-survivin stock with $0.01 \mathrm{M} \mathrm{PBS}$ to reach the desired concentration of 200,100, 50, 25, 12.5, 6.25, 3.125, $0 \mathrm{ng} / \mathrm{ml}$, assigning to $\mathrm{S}_{1}, \mathrm{~S}_{2}, \mathrm{~S}_{3}, \mathrm{~S}_{4}, \mathrm{~S}_{5}, \mathrm{~S}_{6}, \mathrm{~S}_{7}$ and $\mathrm{S}_{0}$, respectively.

Preparation of HRP-labeled $m A b$ and anti-survivin $m A b$-coated MPs. The mAb E6 was selected as detecting antibody and the procedure of labeling it with HRP was performed as described previously (12). The MPs were coated with C6 according to the manufacturer's protocols (Dynal Biotech).

Human urine specimens collection. The urine samples were obtained from Peking University Cancer Hospital (Beijing, China) in 2017. All the cancer patients were histopathologically diagnosed as urothelial carcinoma of bladder or RCC. The staging was determined according to the tumor-nodemetastasis (TNM) classification released by the American Joint Committee on Cancer (AJCC; 7th edition, 2010). The grading for BC was made in accordance with the 2004 World Health Organization (WHO)/International Society of Urologic Pathology (ISUP) grading system. Healthy controls were chosen at the Medical Examination Center of Peking University Cancer Hospital. A total of $200 \mathrm{BC}$ patients and 81 RCC were enrolled in the study and the urinary survivin levels of them were detected. The urine survivin levels of 114 age- and sex-matched healthy donors were also measured. The urinary LAPTM4B levels of them were detected simultaneously. Clean catch midstream urine samples were obtained and centrifuged immediately at 3,000 rpm for $5 \mathrm{~min}$. The supernatant was aliquoted and stored at $-40^{\circ} \mathrm{C}$ until detection. This study was approved by the ethics committee of the Peking University Cancer Hospital. The entire study was conducted according to the Declaration of Helsinki. All of the patients and healthy controls provided written informed consent for participation in the study.

MPs-based CLEIA of urinary survivin and the detection of urine LAPTM4B levels. The procedures of the MPs-based CLEIA are displayed in Fig. 1, and the detailed steps were as follows. First, $50 \mu$ l C6-coated MPs diluted in the antibody diluent was added into each well of the microplates. Then, a mixture of $50 \mu \mathrm{l}$ of either survivin standard series or sample and $50 \mu \mathrm{l}$ of the HRP-labeled E6 (diluted in the antibody diluent) was added into each well of the microplates and incubated in the shaker for $60 \mathrm{~min}$ at room temperature with $300 \mathrm{rpm}$. After that, the MPs which formed sandwich immunocomplexes were magnetically separated for $2 \mathrm{~min}$ and the supernatant containing excess HRP-labeled E6 was removed. Subsequently, the MPs were resuspended in $150 \mu \mathrm{l}$ washing buffer and washing was performed four times. Finally, the chemiluminescent substrate was added into each well and the relative light units (RLU) value was measured.

The detection of urine LAPTM4B was performed using sandwich ELISA following the manufacturer's 


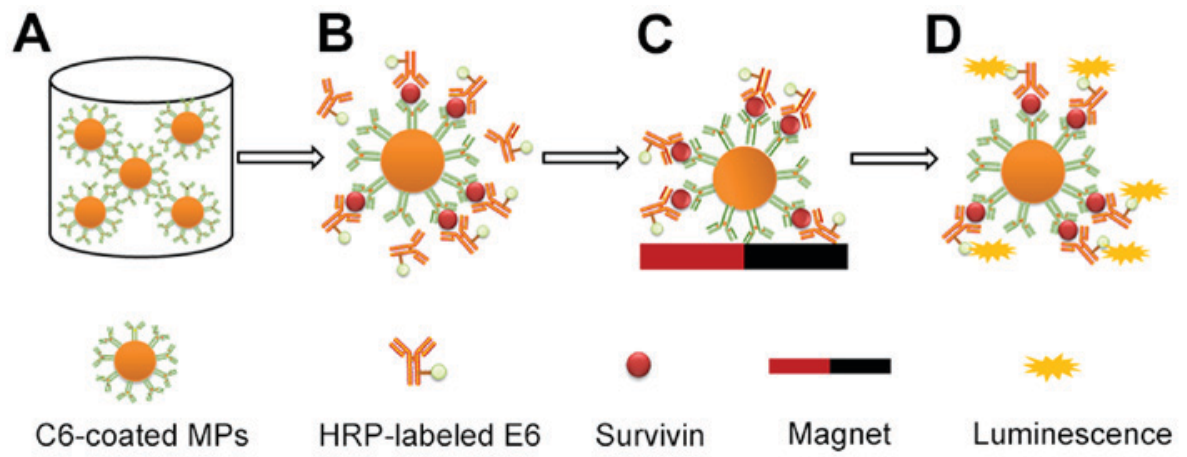

Figure 1. Schematic illustration of the MPs-based chemiluminescence enzyme immunoassay for survivin. (A) A total of $50 \mu 1$ C6-coated MPs were added into each well of microplates. (B) A mixture of $50 \mu \mathrm{l}$ of either survivin standard solution or sample and $50 \mu 1$ of the HRP-labeled E6 was added and reacted with the monoclonal antibodies on MPs. (C) The MPs were magnetically separated and the excess HRP-labeled E6 were removed. (D) Chemiluminescence substrate was added and the relative light units value was detected. MPs, magnetic particles; HRP, horseradish peroxidase.

instructions (Lifespan Biosciences). The detection wavelength of LAPTM4B was $450 \mathrm{~nm}$ by microplate reader.

Development of MPs based CLEIA. We optimized different experimental parameters to gain the widest detection range $\left(\mathrm{RLU}_{\mathrm{S} 1} / \mathrm{RLU}_{\mathrm{S} 0}\right)$ and the highest sensitivity $\left(\mathrm{RLU}_{\mathrm{S} 7} / \mathrm{RLU}_{\mathrm{S} 0}\right)$. The best dilutions of C6-MPs and HRP-labeled E6 were 1:200 and 1:1,200, respectively. The best reaction condition was at room temperature shaking $(400 \mathrm{rpm})$ for $1 \mathrm{~h}$. The optimal substrate volume was $100 \mu \mathrm{l}$ per well and the maximal RLUs were observed immediately after adding the chemiluminescent substrate (avoiding light).

Statistical analysis. Statistical analysis was carried out using SPSS v19.0 software (SPSS, Inc., Chicago, IL, USA). The measurement data were expressed in the form of median (interquartile range). Comparisons of different groups were analyzed by Mann-Whitney U-test for continuous variables. Receiver operating characteristic (ROC) curves were created to evaluate the diagnostic efficiency. MedCalc statistical software was employed for the comparison of ROC curves. We employed bivariate logistic regression to obtain the predictive P-values and used the P-values to build a new ROC curve for the two biomarkers combined. Cut-off value was determined by the optimal Youden's index (sensitivity + specifcity-1). $\mathrm{P}<0.05$ was considered to indicate a statistically significant difference.

\section{Results}

Purification of mAbs against survivin. The mAbs (C6, E6) recognizing different isotopes of survivin were purified. This antibody pair has been tested in a sandwiched ELISA assay. C6 was used as capturing antibody and E6 was detecting antibody. The purity of them would affect the sensitivity and specificity of the proposed method. The purification effect is shown in Fig. 2. There were two straps (heavy and light chains) for each $\mathrm{mAb}$ and almost all of the other proteins were removed.

\section{Method evaluation}

Standard curve and sensitivity. Under the optimal conditions, a standard curve was obtained by four-parameter logistic curve fitting (Fig. 3) with a correlation coefficient of 0.9983 . The sum of the average RLU and 2 standard deviations (SDs)

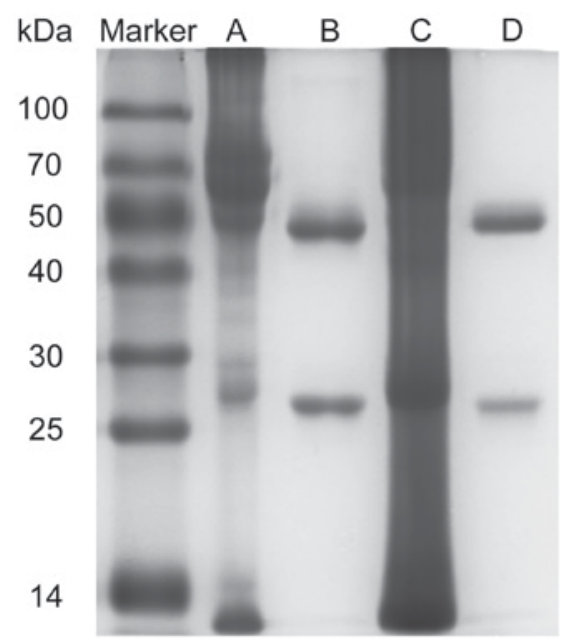

Figure 2. Purification results of the mAbs against survivin by SDS-PAGE. Lane A, unpurified C6; lane B, purified C6; lane C, unpurified E6; and lane D, purified C6. There were only two bands following $\mathrm{mAb}$ purification, and these were heavy and light chains, respectively. mAbs, monoclonal antibodies.

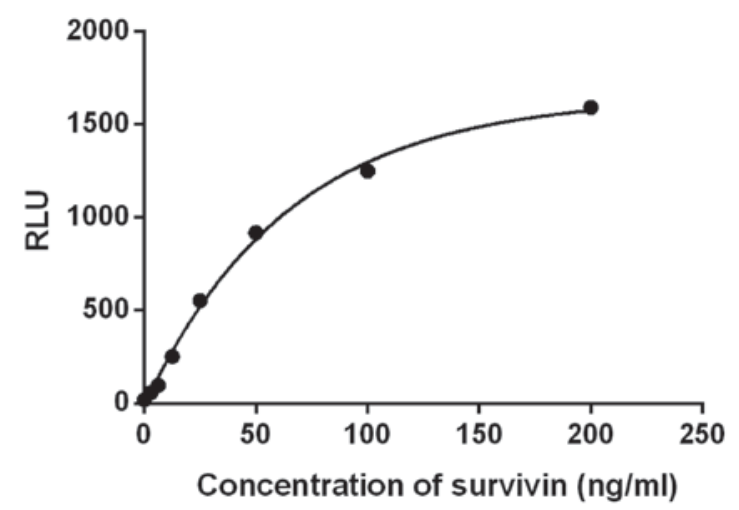

Figure 3. Calibration curve for survivin standards by the proposed magnetic particles-based chemiluminescence enzyme immunoassay method. Four-parameter logistic curve fitting was employed for the fitting of the curve with a correlation coefficient of 0.9983 . RLU, relative light units.

of 10 replicates of $\mathrm{S}_{0}$ was considered as the detection limit. According to the standard curve, the concentration of the detection limit was $0.949 \mathrm{ng} / \mathrm{ml}$. 

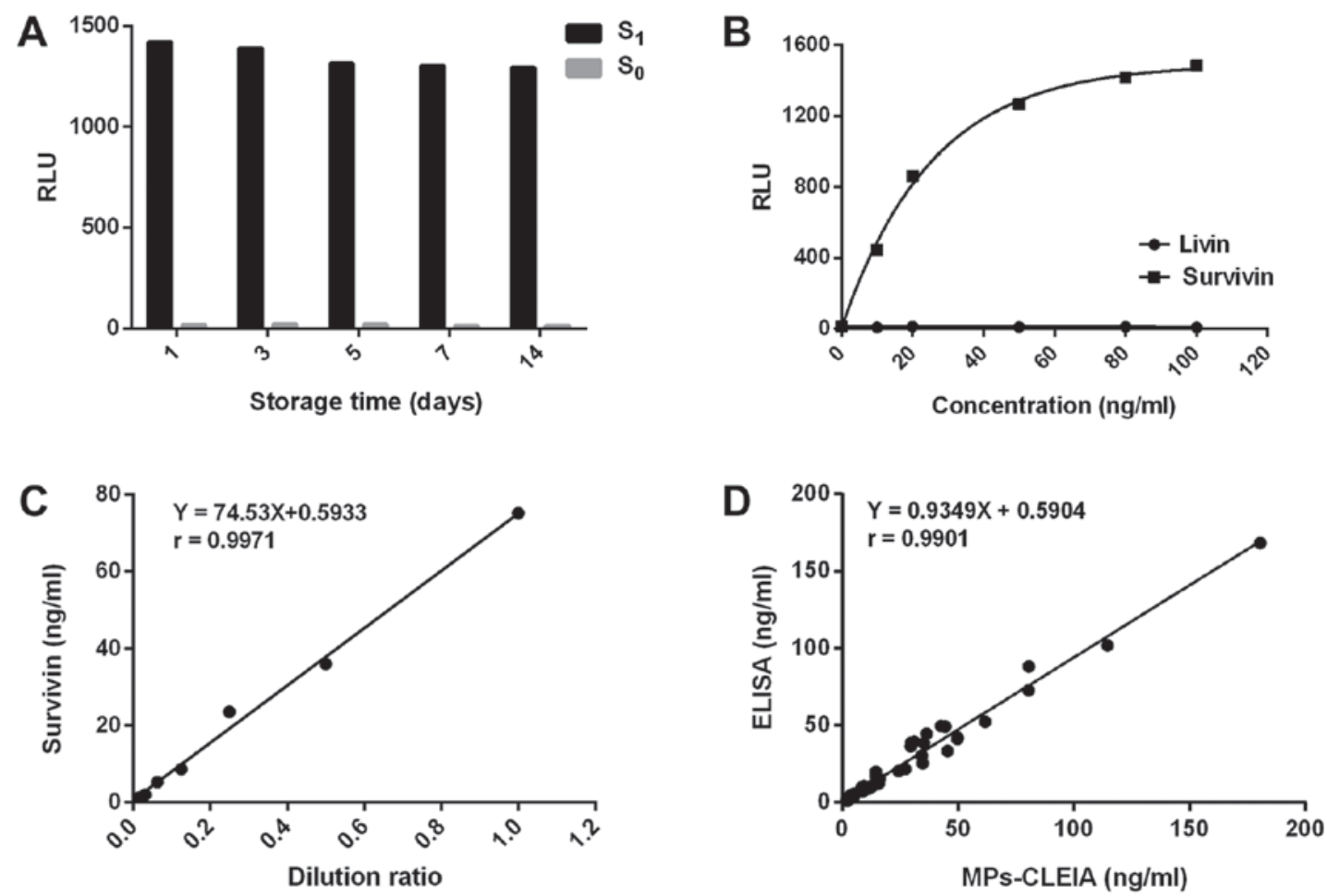

Figure 4. Method evaluation of the MPs-based CLEIA. (A) Detection results of the average RLU of $\mathrm{S}_{1}$ and $\mathrm{S}_{0}$ at different storage times (1,3, 5, 7 and 14 days). In total, $>90 \%$ of the initial response was obtained following MPs storage for 14 days at $4^{\circ} \mathrm{C}$. (B) The average RLU of the assay for survivin and livin over the concentration range 0 to $100 \mathrm{ng} / \mathrm{ml}$. The response of survivin was dependent on its concentration, while livin was not detected. (C) The linearity-dilution effect of the high concentration urine. The association between the concentration of the diluted survivin and the dilution ratios produced a good linear correlation coefficient of 0.9971. (D) Correlation between the results measured by the proposed MPs-CLEIA method and ELISA. The survivin levels in 90 urine samples were determined simultaneously using the proposed MPs-CLEIA method and ELISA. The correlation coefficient between the 2 methods was 0.9901 . RLU, relative light units; MPs, magnetic particles; CLEIA, chemiluminescence enzyme immunoassay; $\mathrm{S}_{1}$ and $\mathrm{S}_{0}, \mathrm{MS}_{2}$-survivin at 200 and $0 \mathrm{ng} / \mathrm{ml}$, respectively.

Stability. The stability of the C6-coated MPs was also investigated, C6-coated MPs were stored at $4^{\circ} \mathrm{C}$ for 14 days. During this period, C6-coated MPs were taken out on day 1, $3,5,7,14$ to detect $S_{1}$ and $S_{0}$. As shown in Fig. 4A, the RLU value showed no obvious decrease and the proposed method retained more than $90 \%$ of its initial response after the storage of C6-coated MPs for 14 days at $4^{\circ} \mathrm{C}$. Therefore, the result indicated that the stability of C6-coated MPs was acceptable within 2 weeks.

Hook effect. As the immunoassay was a one-step procedure, the hook effect was studied. A sample spiked with survivin at extremely high concentration $(1,000 \mathrm{ng} / \mathrm{ml})$ was tested using the MPs-based CLEIA. The RLU value turned out to exceed the upper detection limit and showed no decline. Thus, the pseudo-negative can be avoided successfully in the case of high concentration urine samples.

Precision. Three different concentrations of the urine samples were measured 8 times in one assay to evaluate the intra-assay precision. The same samples were analyzed on different days (5 days) using the same protocol (3 replicates per run) to obtain the inter-assay precision. The urine samples were patient pools. The results showed that the intra-assay $\mathrm{CV}$ was $<7 \%$ and the inter-assay CV was $<10 \%$ (Table I).

Recovery. The accuracy was studied through a recovery test. Different amounts of survivin were added to three human urine samples to obtain high, middle and low distributions and these were detected in triplicate. As shown in Table II, the average recoveries were between 95 and $105 \%$, indicating that the accuracy of the proposed method was satisfactory.

Interferences. The interference of potential endogenous interferents was assessed by overloading three urine samples (survivin=10.96, 59.33 and $93.50 \mathrm{ng} / \mathrm{ml}$ ). And the results showed that the interferences of a final concentration of $1.6 \mathrm{mmol} / \mathrm{l}$ oxalic acid, $2.4 \mathrm{mmol} / \mathrm{l}$ glucose, $2.3 \mathrm{mmol} / 1 \mathrm{vitamin}$ C, $350 \mu \mathrm{mol} / 1$ galactose, $1,000 \mu \mathrm{mol} / 1$ creatinine, $500 \mathrm{mmol} / 1$ urea, and $600 \mathrm{mg} / \mathrm{l}$ albumin were all $<10 \%$ on the survivin MPs-based CLEIA.

Cross-reactivity $(C R)$. The inhibitor of apoptosis (IAP) protein family shows similar structural features and different degrees of homology. Survivin and livin are both members of the family and the specificity of the proposed method was evaluated using livin peptide. The average $\mathrm{CR}$ for livin over 0-100 ng/ml was assessed (Fig. 4B). The CR was calculated as follows: $\mathrm{CR}=100 \times \mathrm{C}_{\text {survivin }} / \mathrm{C}_{\text {cross-reactant }}$, where $\mathrm{C}_{\text {survivin }}$ refers to the concentration of survivin determined by applying the tested cross-reactant signal to the dose-response curve and the $\mathrm{C}_{\text {cross-reactant }}$ refers to the concentration of livin. The results showed that $\mathrm{C} 6$ and E6 did not cross-react with livin.

Linearity-dilution effect. The linearity-dilution effect was studied by selecting a human urine sample with a relatively 
Table I. Intra- and inter-assay variability for survivin.

\begin{tabular}{|c|c|c|c|c|c|c|}
\hline \multirow[b]{2}{*}{ Sample no. } & \multicolumn{3}{|c|}{ Intra-assay } & \multicolumn{3}{|c|}{ Inter-assay } \\
\hline & $\begin{array}{c}\text { No. of } \\
\text { replications }\end{array}$ & $\begin{array}{l}\text { Concentration } \\
(\mathrm{ng} / \mathrm{ml})\end{array}$ & $\mathrm{CV}(\%)$ & $\begin{array}{c}\text { Days of } \\
\text { replication }\end{array}$ & $\begin{array}{l}\text { Concentration } \\
(\mathrm{ng} / \mathrm{ml})\end{array}$ & $\mathrm{CV}(\%)$ \\
\hline 1 & 8 & 7.07 & 6.80 & 5 & 6.52 & 8.28 \\
\hline 2 & 8 & 33.63 & 4.23 & 5 & 32.78 & 9.84 \\
\hline 3 & 8 & 86.71 & 3.08 & 5 & 86.42 & 6.48 \\
\hline
\end{tabular}

$\mathrm{CV}$, coefficient of variation.

Table II. Recovery of survivin in human urine.

\begin{tabular}{lccc}
\hline $\begin{array}{l}\text { Survivin concentration in } \\
\text { human urine }(\mathrm{ng} / \mathrm{ml})\end{array}$ & $\begin{array}{c}\text { Amount of survivin } \\
\text { added }(\mathrm{ng} / \mathrm{ml})\end{array}$ & $\begin{array}{c}\text { Mean measured } \\
\text { concentration }(\mathrm{ng} / \mathrm{ml})\end{array}$ & $\begin{array}{c}\text { Mean } \\
\text { recovery }(\%)\end{array}$ \\
\hline 1.12 & 5 & 5.89 & 95.39 \\
& 30 & 30.15 & 96.78 \\
1.46 & 80 & 6.39 & 98.00 \\
& 5 & 32.96 & 105.00 \\
2.41 & 30 & 82.89 & 101.78 \\
& 80 & 7.48 & 93 \\
& 5 & 31.00 & 95.31 \\
& 30 & 78.62 & 95.27
\end{tabular}

high concentration of $75.14 \mathrm{ng} / \mathrm{ml}$. It was diluted by $\mathrm{S}_{0}$ to obtain a series of concentrations 1/2,1/4, 1/8, 1/16, 1/32 and $1 / 64$ of the original concentration. Each sample was measured in duplicate. The results were shown in Fig. 4C. As can be seen, the relationship between the concentration of the diluted survivin and the dilution ratios had a favorable linear correlation coefficient of 0.9971 .

Reference interval. We collected the urine samples from 114 healthy individuals. Reference interval was determined by nonparametric analysis at $95 \%$ confidence level and the upper reference limit was $2.73 \mathrm{ng} / \mathrm{ml}$ for survivin.

Comparison with ELISA. The ELISA procedure was performed as described previously (12). The proposed method was applied for the determination of survivin in 90 clinical urine samples and the results were compared with those obtained by ELISA (Fig. 4D). There was a good correlation coeffcient of 0.9901 .

\section{Sample analysis}

Urinary survivin in BC and RCC compared with healthy controls. As can be seen in Fig. 5A, urinary survivin in BC [3.65 ng/ml $(3.42 \mathrm{ng} / \mathrm{ml}), \mathrm{P}<0.001]$ and $\mathrm{RCC}[4.23 \mathrm{ng} / \mathrm{ml}$ (7.07 ng/ml), $\mathrm{P}<0.001]$ displayed significantly higher levels than the healthy controls $[1.54 \mathrm{ng} / \mathrm{ml}(3.10 \mathrm{ng} / \mathrm{ml})]$. ROC curves were constructed for $\mathrm{BC}$ and RCC (Fig. 6A and B). The area under the curve (AUC) was 0.771 for $\mathrm{BC}$ and 0.763 for RCC, respectively.

Relationships between urine survivin and clinicopathological characteristics. We analyzed urine survivin levels between different clinicopathological parameters in BC and RCC. The results were shown in Tables III and IV. In BC patients, urine survivin levels were related to the tumor stage $(\mathrm{P}=0.002)$, lymph node metastasis $(\mathrm{P}=0.017)$, distant metastasis $(\mathrm{P}=0.005)$ and tumor size $(\mathrm{P}=0.02)$. In patients with $\mathrm{RCC}$, urinary survivin showed no correlations with any clinicopathological parameters listed in Table IV, which was probably due to the limited number of RCC patients recruited in this study.

Urinary survivin and LAPTM4B in BC and RCC. As shown in Fig. 5B, urine LAPTM4B levels were significantly higher in $\mathrm{BC}[11.20 \mathrm{ng} / \mathrm{ml}(46.70 \mathrm{ng} / \mathrm{ml}), \mathrm{P}<0.001]$ and $\mathrm{RCC}$ patients [8.08 ng/ml $(21.47 \mathrm{ng} / \mathrm{ml}), \mathrm{P}<0.001]$ than in healthy controls [3.90 ng/ml (7.91 ng/ml)]. Fig. 6C and D displayed the ROC curves of LAPTM4B for BC and RCC. The AUCs were 0.738 for $\mathrm{BC}$ and 0.704 for $\mathrm{RCC}$, which showed no significant differences from survivin $(\mathrm{P}>0.05)$. There was no significant correlation between urinary survivin and LAPTM4B $(\mathrm{P}=0.790)$. We combined urinary survivin with LAPTM4B in the preliminary diagnosis of BC and RCC. The ROC curves were shown in Fig. 7, of which the AUCs were 0.842 for BC and 0.920 for RCC. There were statistical differences between the AUCs of 

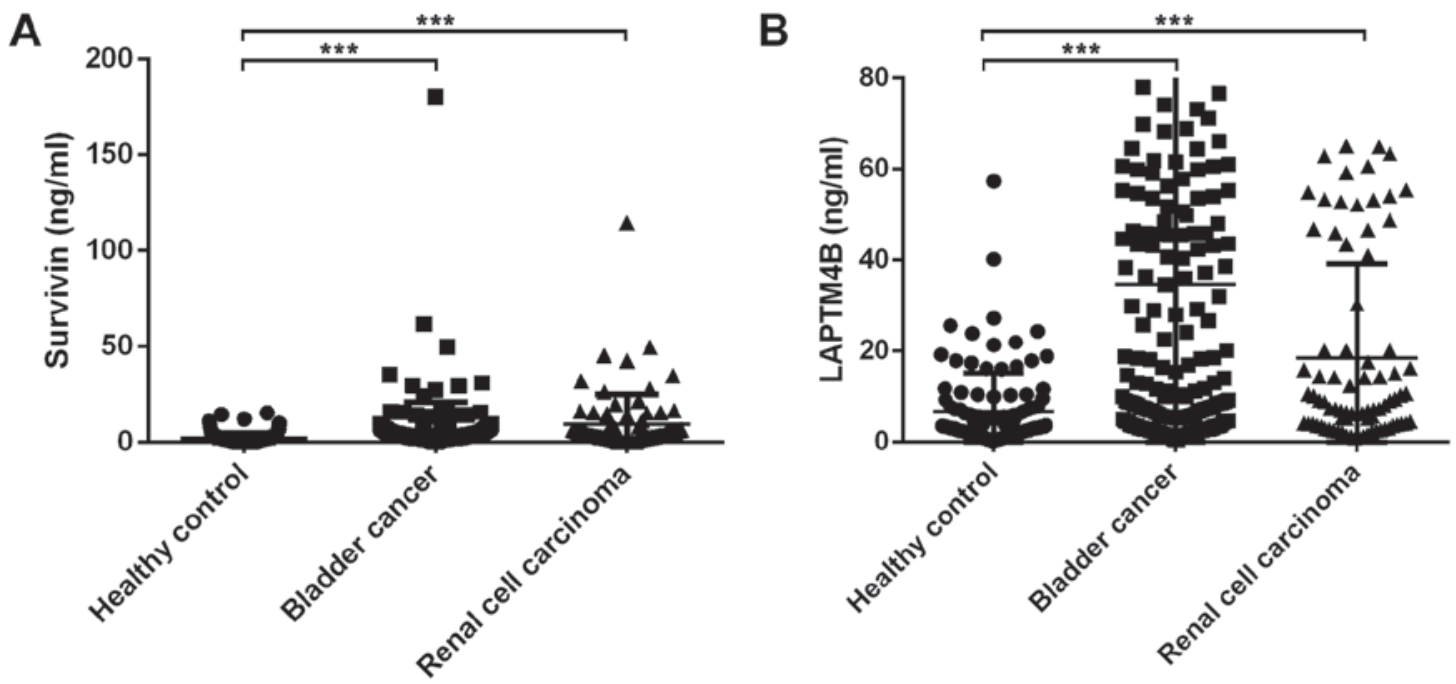

Figure 5. Urinary survivin and LAPTM4B in healthy controls, BC patients and RCC patients. (A) The urinary survivin levels of 114 healthy controls, $200 \mathrm{BC}$ patients and 81 RCC patients were measured. Urine survivin levels in BC and RCC were significantly higher than healthy controls. (B) The urinary LAPTM4B levels of 114 healthy controls, $200 \mathrm{BC}$ patients and 81 RCC patients were measured. Urinary LAPTM4B in BC and RCC was observed in significantly higher levels than in healthy controls. ${ }^{* * * *} \mathrm{P}<0.001$, as indicated. BC, bladder cancer; RCC, renal cell carcinoma; LAPTM4B, lysosome-associated protein transmembrane- $4 \beta$.
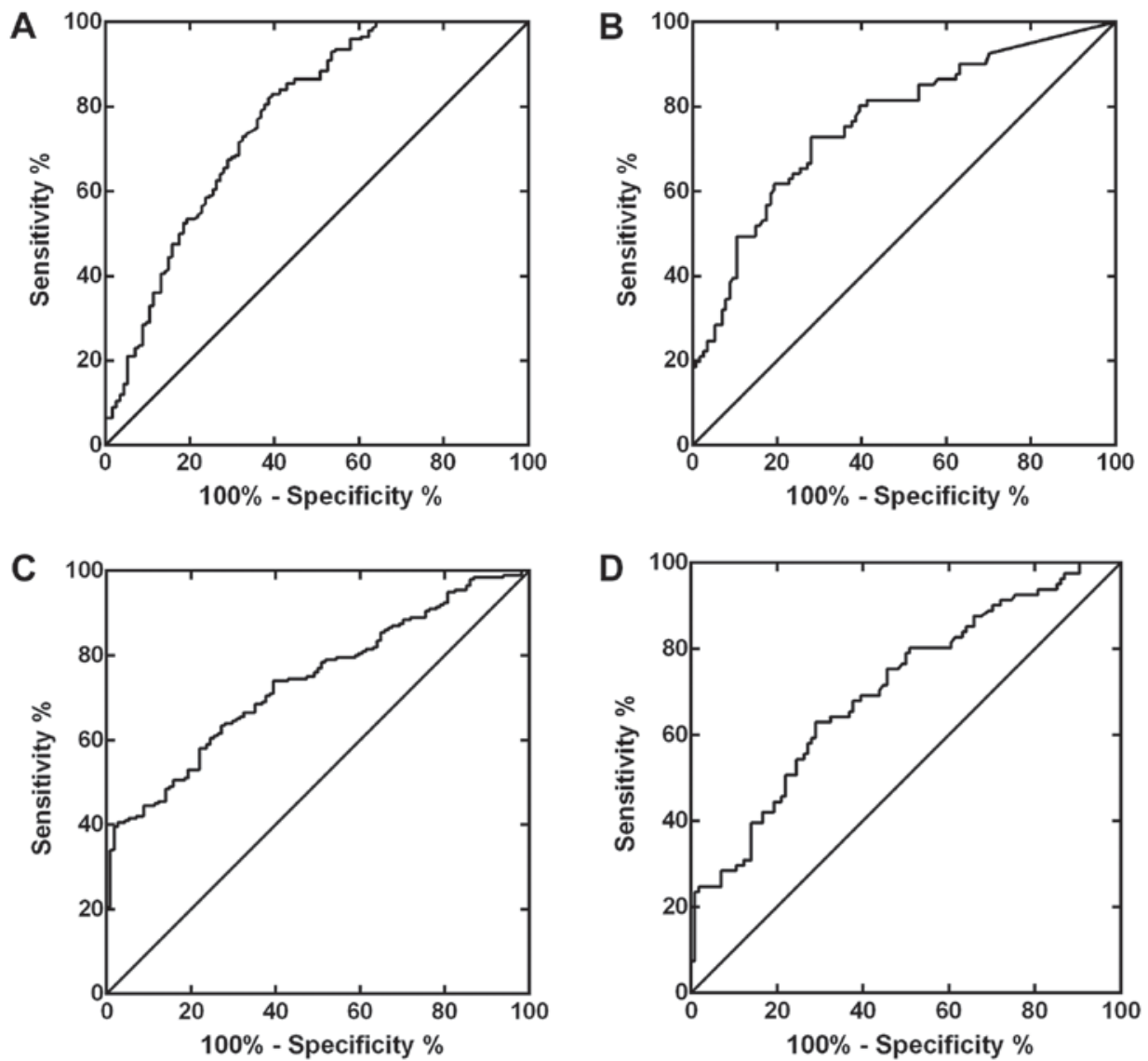

Figure 6. Receiver operating characteristic curves for urinary survivin and LAPTM4B in BC and RCC. (A) Urinary survivin in BC: AUC was 0.771. (B) Urinary survivin in RCC: AUC was 0.763. (C) Urinary LAPTM4B in BC: AUC was 0.738. (D) Urinary LAPTM4B in RCC: The AUC was 0.704. BC, bladder cancer; RCC, renal cell carcinoma; LAPTM4B, lysosome-associated protein transmembrane-4 $\beta$; AUC, area under the curve.

LAPTM4B and the combined evaluation $(\mathrm{P}<0.001$ for $\mathrm{BC}$, $\mathrm{P}=0.0017$ for $\mathrm{RCC}$, respectively), statistical differences were also found between the combination and survivin $(\mathrm{P}<0.001$ for $\mathrm{BC}$, $\mathrm{P}=0.0405$ for $\mathrm{RCC}$, respectively). Table $\mathrm{V}$ gave the sensitivities and specificities of the two markers evaluated separately and jointly. Taken the parameters above into account, the combination of urinary survivin and LAPTM4B could provide a better diagnosis performance for $\mathrm{BC}$ and $\mathrm{RCC}$. 
Table III. Associations between urinary survivin and clinicopathological characteristics in bladder cancer.

\begin{tabular}{|c|c|c|c|}
\hline $\begin{array}{l}\text { Clinicopathological } \\
\text { characteristic }\end{array}$ & $\begin{array}{l}\text { No. of } \\
\text { patients }\end{array}$ & $\begin{array}{l}\text { Survivin } \\
(\mathrm{ng} / \mathrm{ml})\end{array}$ & P-value \\
\hline \multicolumn{4}{|l|}{ Sex } \\
\hline Male & 150 & $3.23(2.91)$ & 0.268 \\
\hline Female & 50 & $3.27(3.00)$ & \\
\hline \multicolumn{4}{|l|}{ Age (years) } \\
\hline$\leq 60$ & 81 & $3.89(3.45)$ & 0.064 \\
\hline$>60$ & 119 & $3.14(2.66)$ & \\
\hline \multicolumn{4}{|l|}{ Stage } \\
\hline $\mathrm{I}+\mathrm{II}$ & 103 & $3.02(2.81)$ & 0.002 \\
\hline III+IV & 97 & $2.81(3.00)$ & \\
\hline \multicolumn{4}{|c|}{ Lymph node metastasis } \\
\hline No & 137 & $3.14(2.71)$ & 0.017 \\
\hline Yes & 63 & $4.00(3.31)$ & \\
\hline \multicolumn{4}{|l|}{ Distant metastasis } \\
\hline No & 144 & $3.11(2.73)$ & 0.005 \\
\hline Yes & 56 & $4.13(4.52)$ & \\
\hline \multicolumn{4}{|l|}{ Tumor size (cm) } \\
\hline$<2$ & 75 & $2.83(2.53)$ & 0.020 \\
\hline$\geq 2$ & 125 & $2.53(2.53)$ & \\
\hline \multicolumn{4}{|l|}{ Grade } \\
\hline Low grade & 43 & $3.03(2.50)$ & 0.187 \\
\hline High grade & 148 & $3.60(3.16)$ & \\
\hline \multicolumn{4}{|l|}{ Muscle invasion } \\
\hline No & 93 & $3.49(2.72)$ & 0.612 \\
\hline Yes & 97 & $2.72(2.72)$ & \\
\hline \multicolumn{4}{|c|}{ Vascular tumor thrombus } \\
\hline Invisible & 32 & $3.81(4.10)$ & 0.441 \\
\hline Visible & 28 & $2.90(3.57)$ & \\
\hline \multicolumn{4}{|l|}{ NMP22 } \\
\hline- & 77 & 3.14 (2.57) & 0.493 \\
\hline+ & 33 & 2.57 (3.58) & \\
\hline \multicolumn{4}{|l|}{ Urine cytology } \\
\hline- & 23 & $3.28(2.18)$ & 0.564 \\
\hline+ & 28 & $3.64(2.50)$ & \\
\hline
\end{tabular}

Data are presented as the mean (interquartile range). NMP22, nuclear matrix protein 22 .

\section{Discussion}

In this study, we presented a simple step MPs-based CLEIA for the detection of urine survivin. As urine has very complex components and the $\mathrm{pH}$ of urine varies, the matrix effect would be a thorny problem $(14,15)$. Some commercial ELISA kits employ sample diluent to solve the problem, but it would take a lot of effort to dilute every single sample. Normally, ELISA costs about 3-4 $\mathrm{h}$ and requires multiple procedures including dilution, incubation, aspirating and washing while the MPs based CLEIA could be done within one and a half
Table IV. Relationships between urinary survivin and clinicopathological characteristics in renal cell carcinoma.

\begin{tabular}{lccc}
\hline $\begin{array}{l}\text { Clinicopathological } \\
\text { characteristic }\end{array}$ & $\begin{array}{c}\text { No. of } \\
\text { patients }\end{array}$ & $\begin{array}{c}\text { Survivin } \\
(\mathrm{ng} / \mathrm{ml})\end{array}$ & P-value
\end{tabular}

\section{Sex}

Male

Female

$59 \quad 4.91(5.60)$

0.222

Age (years)

$$
\begin{aligned}
& \leq 60 \\
& >60
\end{aligned}
$$

Stage

I+II

III+IV

$22 \quad 3.52(9.25)$

Lymph node metastasis

No

Yes

$46 \quad 4.15(10.24) \quad 0.630$

$35 \quad 4.90(4.49)$

$58 \quad 3.97(6.68) \quad 0.530$

$23 \quad 5.84(7.29)$

$66 \quad 3.84(5.09)$

0.128

Distant metastasis

No
Yes

Tumor size $(\mathrm{cm})$

$$
\leq 3
$$

$>3$

$15 \quad 6.33(12.05)$

Fuhrman grade

$$
\begin{aligned}
& \text { 1-2 } \\
& 3-4
\end{aligned}
$$

$70 \quad 3.84(5.09)$

0.238

$11 \quad 6.33(12.05)$

$\begin{array}{lll}33 & 3.16(10.13) & 0.273\end{array}$

$48 \quad 5.02(5.22)$

Vascular tumor thrombus

Invisible

$56 \quad 4.15(6.18)$

0.790

$18 \quad 4.16(18.29)$

$70 \quad 3.97(6.81)$

0.316

Depth of infiltration

T1

T2-T4

$64 \quad 4.56(7.58)$

0.685

Data are presented as the median (interquartile range).

hours. The MPs based CLEIA needs only one-step shaking and the magnetic separation makes solid-liquid phase separation quite convenient. Compared with ELISA, the proposed method provided simplified procedures and rapidity. A recent study by our colleagues presented a streptavidin MPs based immunoassay (12). Though this method has greatly reduced the consuming time of the whole assay, it still needed multiple procedures and the matrix effect of urine remained inevitable. Compared to that, the proposed method in the present study was a one-step process which made the detection of urinary survivin much more convenient. The relatively small proportion of sample in the whole reaction system volume and the higher ionic strength of the antibody diluent which resulted to better buffering capacity greatly lowered the impact of matrix. Consequently, the method evaluation demonstrated its accuracy and precision. One-step immunoassay is normally faced with hook effect $(16,17)$, but the pseudo-negative result did not appear when testing the extremely high concentration of survivin. This is probably due to the sufficient antibodies 
Table V. Cut-off values, sensitivities and specificities of urinary survivin and lysosome-associated protein transmembrane- $4 \beta$ evaluated separately and jointly in BC and RCC.

\begin{tabular}{|c|c|c|c|c|c|c|}
\hline \multirow[b]{2}{*}{ Factor detected } & \multicolumn{2}{|c|}{ Cut-off value (ng/ml) } & \multicolumn{2}{|c|}{ Sensitivity $(\%)$} & \multicolumn{2}{|c|}{ Specificity $(\%)$} \\
\hline & $\mathrm{BC}$ & $\mathrm{RCC}$ & $\mathrm{BC}$ & $\mathrm{RCC}$ & $\mathrm{BC}$ & $\mathrm{RCC}$ \\
\hline Survivin & 1.97 & 2.71 & 83.00 & 72.84 & 60.53 & 71.93 \\
\hline LAPTM4B & 25.69 & 6.16 & 40.50 & 62.96 & 97.37 & 71.05 \\
\hline \multicolumn{7}{|l|}{ Combined } \\
\hline Survivin & 2.39 & 6.26 & 87.50 & 85.19 & 69.3 & 85.96 \\
\hline LAPTM4B & 5.32 & 3.39 & & & & \\
\hline
\end{tabular}

LAPTM4B, lysosome-associated protein transmembrane-4 $\beta$; BC, bladder cancer; RCC, renal cell carcinoma.
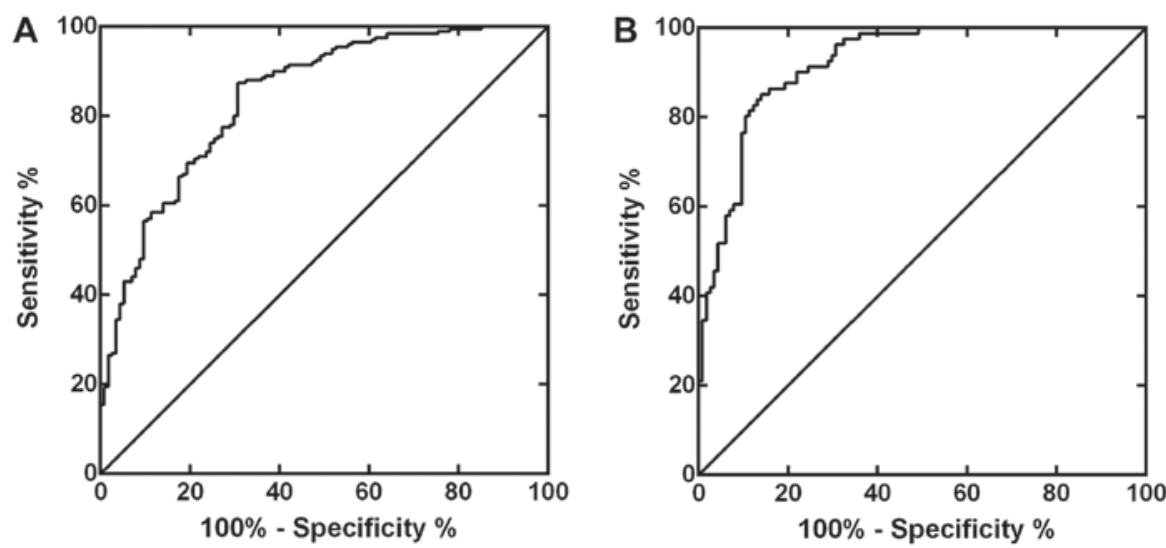

Figure 7. Receiver operating characteristic curves for the combination of urinary survivin and lysosome-associated protein transmembrane- $4 \beta$ in $\mathrm{BC}$ and $\mathrm{RCC}$. (A) BC: AUC was 0.842 , and (B) RCC: AUC was 0.920 . BC, bladder cancer; RCC, renal cell carcinoma; AUC, area under the curve.

coated on the large specific surface of MPs $(16,17)$. In addition, because of less spatial hindrance underwent by antibodies on the MPs surface, the antibody's biological activity could be reserved efficiently (18).

Survivin mRNA measurement (19) and immunohistochemical (IHC) staining of survivin (20) demonstrated the higher expression of survivin in $\mathrm{BC}$. The diagnostic value of urine survivin for $\mathrm{BC}$ has been validated (21-23), which is accorded with the findings of our study. Employing the proposed method, we also found that urinary survivin was related to the tumor stage, lymph node metastasis, distant metastasis and tumor size in $\mathrm{BC}$, which indicated that urinary survivin could also monitor the development and metastasis state of BC. These results are partially consistent with the studies of Chang et al (12) and Gogalic et al (21). The expression of survivin in RCC by IHC technique has been investigeted (24-26), but there were few researches about the diagnostic value of urinary survivin for RCC. In this study, we proposed the possibility of urine survivin serving as a potential biological marker for the preliminary diagnosis of RCC. Some researches indicated that in RCC survivin expression by IHC staining was associated with tumor stage and grade $(25,27)$, and another study found that survivin expression was also correlated with lymph node metastasis (26). But in our study, no associations were found between urinary survivin and clinicopathological features in RCC patients. One reason might be the limited number of RCC patients enrolled and the very complex urine composition (28) would probably impose serious impacts on the results. In addition, IHC staining is a direct measurement of suvivin expression of the tumor while the urinary survivin is secreted by the tumor and the protein needs to pass through the glomerular filtration barrier. Thus, the relationships between urine survivin and the clinicopathological features would not be the same as the results of IHC staining of RCC. Interestingly, Baytekin et al (29) found no correlation between survivin expression and stage, but they indicated an inverse correlation between survivin expression and tumor grade. Hence, the relationship between survivin and clinicopathological parameters of RCC should be further investigated.

LAPTM4B was found to be overexpressed in various solid tumors and was associated with the prognosis of the tumors (30-33). But the potential diagnostic value of LAPTM4B levels in urine has not been studied yet. In this study, we tested the urinary LAPTM4B in BC and RCC. The results showed that the urine LAPTM4B levels were elevated in the patients compared with healthy controls, and the ROC curves demonstrated urinary LAPTM4B was of certain value for the preliminary diagnosis of $\mathrm{BC}$ and RCC. It is the first time to investigate the possibility of urinary LAPTM4B as a potential biomarker for the preliminary diagnosis of $\mathrm{BC}$ and RCC. 
We also found that the combination of urinary survivin and LAPTM4B could give a better diagnostic performance. The AUCs of the combined evaluation was bigger than LAPTM4B or survivin alone for both malignant diseases. Thecombined evaluation showed better sensitivities and specificities. A recent study by Sha Li et al (34) demonstrated that nuclear survivin protein expression were linearly correlated with LAPTM4B in breast cancer. We investigated the urinary survivin and LAPTM4B simultaneously in BC and RCC for the first time. But in our study, urinary survivin did not have correlation with LAPTM4B. Survivin is a $16.5 \mathrm{kDa}$ protein and the molecular weight of LAPTM4B is $35 \mathrm{kDa}$, which makes them small enough to pass through the glomerular filtration barrier and then could be detected in urine. But there are also a lot of exogenous and endogenous interferences along with the process of urine formation and sample collection $(3,35)$. As a result, the urinary survivin and LAPTM4B could not directly reflect the expression of survivin and LAPTM4B in the tumor tissue, which may explain the inconsistency between the study of Sha Li et al (34) and our findings. This inconsistency might also due to the heterogeneity in different organs. For example, another study in human liver cell line did not indicate the relationship between suvivin and LAPTM4B (36). Therefore, the relationships between urinary survivin and LAPTM4B in BC and RCC need further investigation.

There are three major molecular sub-types of urothelial carcinoma: Urobasal, Genomically Unstable and SCC-like (37). Urobasal tumors show frequent expression of FGFR3, CCND1, KRT5, CDH3 (P-cadherin), CDH1 (E-cadherin) and maintain a urothelial differentiation axis consisting of PPARG/RXRA, FOXA1/GATA3 and anterior HOXA and HOXB genes. Genomically Unstable tumors are characterized by RB1 deletions, TP53 mutations and high ERBB2, CDH1 (E-cadherin) expression. SCC-like tumors demonstrate enhanced expression of KRT5, EGFR and $\mathrm{CDH} 3$ (P-cadherin). Both Genomically Unstable and SCC-like tumors show increased proliferative activity via the PLK1-FOXM1 axis $(37,38)$. CCND1 could bind to the survivin promoter region and activate it $(39,40)$. The expression levels of CCND1 and survivin have proven to be elevated in various tumors $(41,42)$. Survivin is a downstream target molecule of Wnt/ $\beta$-catenin signaling and inhibition of CDH3 (P-cadherin) could induce the down-regulation of $\beta$-catenin (43), which suggests a positive correlation between $\mathrm{CDH} 3$ (P-cadherin) and survivin expression. Previous research showed abberrant CDH1 (E-cadherin) staining was associated with overexpression of survivin in pTa urothelial bladder carcinoma (44). Survivin promoter interferes with the binding of GATA3 and GATA3 might play a role in survivin expression (45). Tumor suppressor protein $\mathrm{pRB}$ can repress survivin transcription through interacting with survivin promoter, which indicates RB1 deletions could lead to elevated survivin expression (46). Wild-type p53 is known to repress survivin expression at both mRNA and protein levels while mutant p53 had little effect on survivin repression (47). It has been proven that EGFR could upregulate survivin expression via the PI-3 kinase pathway (48). LAPTM4B overexpression was found to correlate with EGFR activation (49) and LAPTM4B could enhance and prolong EGFR signaling through inhibiting EGF-induced EGFR intraluminal sorting and lysosomal degradation (50). PLK1-FOXM1 axis regulates the expression of survivin which is one of its down-stream targets (51). Thus, survivin and LAPTM4B are closely related to the molecular sub-types of BC.

In conclusion, we established a novel simple step MPs-based CLEIA for the detection of urinary survivin and applied it to the preliminary diagnosis of BC and RCC. Urinary survivin was proved to be related to the tumor stage, lymph node metastasis, distant metastasis and tumor size in BC, which indicated that urinary survivin could monitor the tumor development and metastasis to a certain degree in BC. Our findings also demonstrated that urinary survivin and LAPTM4B could be of certain value for the preliminary diagnosis of $\mathrm{BC}$ and RCC. Additionally, the combination of them would present a better diagnostic performance. However, this study is limited by the sample size and the lack of external quality assessment of the proposed method. A larger sample size is needed to further validate our findings.

\section{Acknowledgements}

Not applicable.

\section{Funding}

The present study was supported by The National Natural Science Foundation of China (grant no. 81572910), The Capital Healthy Development Special Fund (grant no. 2011-1009-03) and The Capital Laboratory Medicine Clinical Characteristic Fund (grant no. Z121107005112004).

\section{Availability of data and materials}

The datasets used and analyzed during the current study are available from the corresponding author on reasonable request.

\section{Authors' contributions}

YY acquired the data and drafted the manuscript. JX analyzed and interpreted the patient data. QYZ was a major contributor in conception and design, and gave final approval of the version to be published. All authors read and approved the final manuscript.

\section{Ethics approval and consent to participate}

The animal experiments were approved by the Animal Care Committee of Peking University (Beijing, China). The experiments involving patient samples were approved by the Ethics Committee of the Peking University Cancer Hospital (Beijing, China). All of the patients and healthy controls provided written informed consent for participation in the study.

\section{Consent for publication}

All of the patients and healthy controls provided written informed. 


\section{Competing interests}

The authors declare no conflict of interest.

\section{References}

1. Ferlay J, Soerjomataram I, Dikshit R, Eser S, Mathers C, Rebelo M, Parkin DM, Forman D and Bray F: Cancer incidence and mortality worldwide: Sources, methods and major patterns in GLOBOCAN 2012. Int J Cancer 136: E359-E386, 2015.

2. Siegel RL, Miller KD and Jemal A: Cancer Statistics, 2017. CA Cancer J Clin 67: 7-30, 2017.

3. Fiedler GM, Baumann S, Leichtle A, Oltmann A, Kase J, Thiery $\mathrm{J}$ and Ceglarek U: Standardized peptidome profiling of human urine by magnetic bead separation and matrix-assisted laser desorption/ionization time-of-flight mass spectrometry. Clin Chem 53: 421-428, 2007.

4. Saito M, Kimoto M, Araki T, Shimada Y, Fujii R, Oofusa K, Hide M, Usui $\mathrm{T}$ and Yoshizato $\mathrm{K}$ : Proteome analysis of gelatin-bound urinary proteins from patients with bladder cancers. Eur Urol 48: 865-871, 2005.

5. Chou R, Gore JL, Buckley D, Fu R, Gustafson K, Griffin JC, Grusing S and Selph S: Urinary biomarkers for diagnosis of bladder cancer: A systematic review and meta-analysis. Ann Intern Med 163: 922-931, 2015.

6. Guo A, Wang X, Gao L, Shi J, Sun C and Wan Z: Bladder tumour antigen (BTA stat) test compared to the urine cytology in the diagnosis of bladder cancer: A meta-analysis. Can Urol Assoc J 8: E347-E352, 2014.

7. Pichler R, Tulchiner G, Fritz J, Schaefer G, Horninger W and Heidegger I: Urinary UBC rapid and NMP22 test for bladder cancer surveillance in comparison to urinary cytology: Results from a prospective single-center study. Int J Med Sci 14: 811-819, 2017.

8. Papale M, Vocino G, Lucarelli G, Rutigliano M, Gigante M, Rocchetti MT, Pesce F, Sanguedolce F, Bufo P, Battaglia M, et al: Urinary RKIP/p-RKIP is a potential diagnostic and prognostic marker of clear cell renal cell carcinoma. Oncotarget 8: 40412-40424, 2017.

9. Altieri DC: Survivin-The inconvenient IAP. Semin Cell Dev Biol 39: 91-96, 2015

10. Abd El-Hakim TF, El-Shafie MK, Abdou AG, Azmy RM, El-Naidany SS and Badr El-Din MO: Value of urinary survivin as a diagnostic marker in bladder cancer. Anal Quant Cytopathol Histpathol 36: 121-127, 2014.

11. Meng Y, Wang L, Chen D, Chang Y, Zhang M, Xu JJ, Zhou R and Zhang QY: LAPTM4B: An oncogene in various solid tumors and its functions. Oncogene 35: 6359-6365, 2016.

12. Chang Y, Xu J and Zhang Q: Microplate magnetic chemiluminescence immunoassay for detecting urinary survivin in bladder cancer. Oncol Lett 14: 4043-4052, 2017.

13. Wang Y, Zhang QY and Wang YM: Cloning of survivin gene and preparation its monoclonal antibodies as well as checking survivin expression in liver carcinoma cells. Chin J Lab Med 29: 258-262, 2006 (In Chinese).

14. Chatziharalambous D, Lygirou V, Latosinska A, Stravodimos K, Vlahou A, Jankowski V and Zoidakis J: Analytical performance of ELISA assays in urine: One more bottleneck towards biomarker validation and clinical implementation. PLoS One 11: e0149471, 2016.

15. Thway T and Salimi-Moosavi H: Evaluating the impact of matrix effects on biomarker assay sensitivity. Bioanalysis 6: 1081-1091, 2014.

16. Wang X, Lin JM and Ying X: Evaluation of carbohydrate antigen 50 in human serum using magnetic particle-based chemiluminescence enzyme immunoassay. Anal Chim Acta 598: 261-267, 2007.

17. Zhang Q, Wang X, Li Z and Lin JM: Evaluation of alpha-fetoprotein (AFP) in human serum by chemiluminescence enzyme immunoassay with magnetic particles and coated tubes as solid phases. Anal Chim Acta 631: 212-217, 2009.

18. Wang X, Zhang QY, Li ZJ, Ying XT and Lin JM: Development of high-performance magnetic chemiluminescence enzyme immunoassay for alpha-fetoprotein (AFP) in human serum. Clin Chim Acta 393: 90-94, 2008.

19. Horstmann M, Bontrup H, Hennenlotter J, Taeger D, Weber A, Pesch B, Feil G, Patschan O, Johnen G, Stenzl A and Brüning T: Clinical experience with survivin as a biomarker for urothelial bladder cancer. World J Urol 28: 399-404, 2010.
20. Chen HA, Su CM, Hsieh HY, Tung CL, Hsu CD, Wang YH and Shen $\mathrm{CH}$ : Clinical significance of survivin expression in patients with urothelial carcinoma. Dis Markers 2014: 574985, 2014.

21. Gogalic S, Sauer U, Doppler S and Preininger C: Bladder cancer biomarker array to detect aberrant levels of proteins in urine. Analyst 140: 724-735, 2015.

22. Schmidt J, Propping C, Siow WY, Lohse-Fischer A, Toma M, Baldauf-Twelker A, Hakenberg OW, Wirth MP and Fuessel S: Diagnostic and prognostic value of bladder cancer-related transcript markers in urine. J Cancer Res Clin Oncol 142: 401-414, 2016.

23. Sah NK and Seniya C: Survivin splice variants and their diagnostic significance. Tumour Biol 36: 6623-6631, 2015.

24. Zamparese R, Pannone G, Santoro A, Lo Muzio L, Corsi F, Pedicillo MC, Scillitani EL, Tortorella S, Staibano S, Piscuoglio S, et al: Survivin expression in renal cell carcinoma. Cancer Invest 26: 929-935, 2008

25. Byun SS, Yeo WG, Lee SE and Lee E: Expression of survivin in renal cell carcinomas: Association with pathologic features and clinical outcome. Urology 69: 34-37, 2007.

26. Lei Y, Geng Z, Guo-Jun W, He W and Jian-Lin Y: Prognostic significance of survivin expression in renal cell cancer and its correlation with radioresistance. Mol Cell Biochem 344: 23-31, 2010.

27. Shi ZG, Li SQ, Li ZJ, Zhu XJ, Xu P and Liu G: Expression of vimentin and survivin in clear cell renal cell carcinoma and correlation with p53. Clin Transl Oncol 17: 65-73, 2015.

28. Adachi J, Kumar C, Zhang Y, Olsen JV and Mann M: The human urinary proteome contains more than 1500 proteins, including a large proportion of membrane proteins. Genome Biol 7: R80, 2006.

29. Baytekin F, Tuna B, Mungan U, Aslan G and Yorukoglu K: Significance of P-glycoprotein, p53, and survivin expression in renal cell carcinoma. Urol Oncol 29: 502-507, 2011.

30. Yang Y, Yang H, McNutt MA, Xiong F, Nie X, Li L and Zhou R: LAPTM4B overexpression is an independent prognostic marker in ovarian carcinoma. Oncol Rep 20: 1077-1083, 2008.

31. Zhou L, He XD, Cui QC, Zhou WX, Qu Q, Zhou RL, Rui JA and Yu JC: Expression of LAPTM4B-35: A novel marker of progression, invasiveness and poor prognosis of extrahepatic cholangiocarcinoma. Cancer Lett 264: 209-217, 2008.

32. Kang Y, Yin M, Jiang W, Zhang H, Xia B, Xue Y and Huang Y: Overexpression of LAPTM4B-35 is associated with poor prognosis in colorectal carcinoma. Am J Surg 204: 677-683, 2012.

33. Yang H, Xiong FX, Lin M, Yang Y, Nie X and Zhou RL: LAPTM4B-35 overexpression is a risk factor for tumor recurrence and poor prognosis in hepatocellular carcinoma. J Cancer Res Clin Oncol 136: 275-281, 2010.

34. Li S, Wang L, Meng Y, Chang Y, Xu J and Zhang Q: Increased levels of LAPTM4B, VEGF and survivin are correlated with tumor progression and poor prognosis in breast cancer patients. Oncotarget 8: 41282-41293, 2017.

35. Zerefos PG and Vlahou A: Urine sample preparation and protein profiling by two-dimensional electrophoresis and matrix-assisted laser desorption ionization time of flight mass spectroscopy. Methods Mol Biol 428: 141-157, 2008.

36. Li L, Shan Y, Yang H, Zhang S, Lin M, Zhu P, Chen XY, Yi J, McNutt MA, Shao GZ and Zhou RL: Upregulation of LAPTM4B-35 promotes malignant transformation and tumorigenesis in L02 human liver cell line. Anat Rec (Hoboken) 294: 1135-1142, 2011.

37. Sjödahl G, Lövgren K, Lauss M, Patschan O, Gudjonsson S, Chebil G, Aine M, Eriksson P, Månsson W, Lindgren D, et al: Toward a molecular pathologic classification of urothelial carcinoma. Am J Pathol 183: 681-691, 2013.

38. Eriksson P, Aine M, Veerla S, Liedberg F, Sjödahl G and Höglund M: Molecular subtypes of urothelial carcinoma are defined by specific gene regulatory systems. BMC Med Genomics 8: 25, 2015.

39. Li Z, Li X, Li C, Su Y, Fang W, Zhong C, Ji W, Zhang Q and Su C: Transcription factor OCT4 promotes cell cycle progression by regulating CCND1 expression in esophageal carcinoma. Cancer Lett 354: 77-86, 2014.

40. Cao L, Li C, Shen S, Yan Y, Ji W, Wang J, Qian H, Jiang X, Li Z, Wu M, et al: OCT4 increases BIRC5 and CCND1 expression and promotes cancer progression in hepatocellular carcinoma. BMC Cancer 13: 82, 2013 . 
41. Elmegeed GA, Yahya SM, Abd-Elhalim MM, Mohamed MS Mohareb RM and Elsayed GH: Evaluation of heterocyclic steroids and curcumin derivatives as anti-breast cancer agents: Studying the effect on apoptosis in MCF-7 breast cancer cells. Steroids 115: 80-89, 2016.

42. Diaz A, Valera A, Carrera C, Hakim S, Aguilera P, García A, Palou J, Puig S, Malvehy J and Alos L: Pigmented spindle cell nevus: Clues for differentiating it from spindle cell malignant melanoma. A comprehensive survey including clinicopathologic, immunohistochemical, and FISH studies. Am J Surg Pathol 35: 1733-1742, 2011.

43. Sun L, Hu H, Peng L, Zhou Z, Zhao X, Pan J, Sun L, Yang Z and Ran Y: P-cadherin promotes liver metastasis and is associated with poor prognosis in colon cancer. Am J Pathol 179: 380-390, 2011.

44. Breyer J, Gierth M, Shalekenov S, Aziz A, Schäfer J, Burger M, Denzinger S, Hofstädter F, Giedl C and Otto W: Epithelial-mesenchymal transformation markers E-cadherin and survivin predict progression of stage pTa urothelial bladder carcinoma. World J Urol 34: 709-716, 2016.

45. Rodriguez L, Villalobos X, Dakhel S, Padilla L, Hervas R, Hernández JL, Ciudad CJ and Noé V: Polypurine reverse Hoogsteen hairpins as a gene therapy tool against survivin in human prostate cancer PC 3 cells in vitro and in vivo. Biochem Pharmacol 86: 1541-1554, 2013.

46. Jiang Y, Saavedra HI, Holloway MP, Leone G and Altura RA: Aberrant regulation of survivin by the $\mathrm{RB} / \mathrm{E} 2 \mathrm{~F}$ family of proteins. J Biol Chem 279: 40511-40520, 2004.
47. Mirza A, McGuirk M, Hockenberry TN, Wu Q, Ashar H, Black S, Wen SF, Wang L, Kirschmeier P, Bishop WR, et al: Human survivin is negatively regulated by wild-type p53 and participates in p53-dependent apoptotic pathway. Oncogene 21: 2613-2622, 2002.

48. Wang Q and Greene MI: EGFR enhances Survivin expression through the phosphoinositide 3 (PI-3) kinase signaling pathway. Exp Mol Pathol 79: 100-107, 2005.

49. Tian M, Chen Y, Tian D, Qiao X, Ma Z and Li J: Beclin1 antagonizes LAPTM4B-mediated EGFR overactivation in gastric cancer cells. Gene 626: 48-53, 2017.

50. Tan X, Sun Y, Thapa N, Liao Y, Hedman AC and Anderson RA: LAPTM4B is a PtdIns(4,5)P2 effector that regulates EGFR signaling, lysosomal sorting, and degradation. EMBO J 34: $475-490,2015$.

51. Momeny M, Zarrinrad G, Moghaddaskho F, Poursheikhani A, Sankanian G, Zaghal A, Mirshahvaladi S, Esmaeili F, Eyvani H, Barghi F, et al: Dacomitinib, a pan-inhibitor of ErbB receptors, suppresses growth and invasive capacity of chemoresistant ovarian carcinoma cells. Sci Rep 7: 4204, 2017.

(i) $\odot$ This work is licensed under a Creative Commons Attribution-NonCommercial-NoDerivatives 4.0 International (CC BY-NC-ND 4.0) License. 